\title{
Barriers to Adopting and Implementing Local-Level Tobacco Control Policies
}

\author{
Travis D. Satterlund • Diana Cassady • \\ Jeanette Treiber $\cdot$ Cathy Lemp
}

Published online: 31 December 2010

(c) The Author(s) 2010. This article is published with open access at Springerlink.com

\begin{abstract}
Although California communities have been relatively successful in adopting and implementing a wide range of local tobacco control policies, the process has not been without its setbacks and barriers. Little is known about local policy adoption, and this paper examines these processes related to adopting and implementing outdoor smoke-free policies, focusing on the major barriers faced by local-level tobacco control organizations in this process. Ninety-six projects funded by the California Tobacco Control Program submitted final evaluation reports pertaining to an outdoor smoking objective, and the reports from these projects were analyzed. The barriers were grouped in three primary areas: politically polarizing barriers, organizational barriers, and local political orientation. The barriers identified in this study underscore the need for an organized action plan in adopting local tobacco policy. The authors also suggest potential strategies to offset the barriers, including: (1) having a "champion" who helps to carry an objective forward; (2) tapping into a pool of youth volunteers; (3) collecting and using local data as a persuasive tool; (4) educating the community in smoke-free policy efforts; (5) working strategically within the local political climate; and (6) demonstrating to policymakers the constituent support for proposed policy.
\end{abstract}

Keywords Smoke-free policy - Secondhand smoke · Tobacco use $\cdot$ California

T. D. Satterlund $(\bowtie) \cdot$ D. Cassady $\cdot$ J. Treiber $\cdot$ C. Lemp Center for Evaluation and Research, University of California, Davis, 1616 DaVinci Ct., Davis, CA 95618, USA

e-mail: tdsatter@ucdavis.edu

\section{Introduction}

The dangers of secondhand smoke are well documented $[1,2]$, and this research has helped to produce widesweeping changes, including the passage of federal, state, and community level smoke-free laws intended to protect the public from associated risks [3]. Since the passage of the nation's first workplace tobacco control policy-California's Indoor Workplace Smoke-free Act of 1994-California has successfully expanded its application by enacting statewide laws to a wide array of smoking venues including bars and gaming places, tot lots, school grounds, the outside perimeters of government buildings and outdoor spaces $[4,5]$. With scientific evidence demonstrating the hazards of outdoor secondhand smoke [6], local jurisdictions in California have likewise enacted policies and ordinances protecting communal areas in and around multi-unit housing complexes, perimeters of public businesses, sidewalks, parks, beaches, sporting facilities, and outdoor dining, while some municipalities have banned outdoor public smoking altogether. Currently, over 150 jurisdictions in California have smoke-free outdoor policies above and beyond state laws [5].

Yet, the process of passing local legislation is not without setbacks, challenges, and barriers. Thus, while California jurisdictions have been relatively successful in adopting and implementing a wide range of tobacco control policies, securing outdoor smoke-free local legislation has not always been easy. Academic journals are replete with articles analyzing the legislative process and untangling the minutia of policy enactment, yet little is known about the process of local policy adoption, and less still concerning those issues confronted by local organizations in attempting to secure passage of local policies. This paper examines some of the processes related to adopting and implementing outdoor 
smoke-free local policies. We focus on the major barriers and challenges faced by local-level tobacco control projects charged with the on-the-ground job of gaining the support of community members, constituents, and ultimately, the policymakers who possess the authority to enact local ordinances. In identifying these challenges and barriers, we provide recommendations for jurisdictions that may be working to enact smoke-free outdoor policies in their local communities.

\section{Method}

Background: The California Tobacco Control Program and its Local Projects

The California Tobacco Control Program (CTCP) administers the funds of the $\$ 0.25$ tobacco tax that California voters approved through Proposition 99 in 1988. The funds are used for a comprehensive tobacco control program in California communities, which is carried out by local health departments that receive guaranteed funding, and by competitive local project grantees. CTCP funds over 100 local projects to engage in local policy work to reduce exposure to the harmful effects of secondhand smoke. All projects develop a multi-year plan that determines an agency's local tobacco control objectives and outlines the strategies and scope of work for achieving them. CTCP provides a general set of strategies, aiming at social norm changes within the communities [4].

Funded agencies can choose from an extensive selection of topics that include countering pro-tobacco influences, reducing exposure to secondhand smoke, reducing the availability of tobacco, and supporting cessation efforts. Every 3 years the local projects perform a community assessment to determine which indicators may be the most suitable for developing a campaign that involves voluntary or government policies related to smoking.

\section{Study Data}

The data analyzed in this article were drawn from two cycles (2004-2007 and 2007-2010) of final evaluation reports submitted by local tobacco control projects funded by CTCP. The local projects write 10-30 page final evaluation reports at the end of their funding cycle, compiling information pertaining to the local project's activities, interventions, strategies, evaluation methods and outcomes in meeting their proposed objectives. Local projects are also asked to include the results of process measures in their final evaluation reports, which would include public opinion polls, public intercept surveys and key informant interviews. The goals of the final evaluation report are manifold. While it serves as an accountability piece for the work performed, it is also a learning tool for the agencies themselves, including their stakeholders, and for other agencies that may work on similar objectives. In order to ensure that the information contained in the final evaluation reports can easily be accessed by others and used for comparative purposes, CTCP has developed specific guidelines for these reports. Because a local project's objectives are not always met, CTCP aims to learn from both met and unmet objectives. For this reason, final evaluation reports that tell the project's 3 year story are extremely useful, and provide the primary data used for this paper.

Approximately 381 final evaluation reports were submitted in 2007 and 2010. Of these reports, 96 projects carried out plans pertaining to an outdoor smoking objective, and are the basis for this analysis. The vast majority of local policy efforts fell into one of five major categories: outdoor recreational facilities, multi-unit housing, public events, outdoor worksites, entryways, and service areas (bus stops, ticket lines, etc.). This paper examines the challenges and barriers local projects experienced in adopting and implementing smoke-free policies.

In analyzing the final evaluation reports, we used the information included in the reports as primary data, coding the reports, and focusing on barriers and challenges faced by the local projects. Once passages from final evaluation reports were fully coded, the data were examined to uncover recurring themes and patterns in relation to the specific issues local organizations dealt with in attempting to secure passage of smoke-free policy. Particular attention was paid to the contextual factors crucial to the relative success or failure to adopt and implement policy.

\section{Results}

Three major themes emerged as primary barriers facing local project's attempts at enacting local smoke-free policy: (1) organizational barriers, (2) political polarization, and (3) local political orientation. Within each of these main categories were a subset of issues that halted policy adoption altogether, made local adoption difficult, or impeded enforcement of a newly adopted policy.

\section{Organizational Barriers}

A frequent barrier faced by local projects concerned organizational factors, both within project agencies and among organizations and elected bodies that local projects worked with. These organizational challenges many times attributed to lack of adoption of outdoor smoke-free policy, or else created huge hindrances that required enormous time and resources to overcome. 


\section{The Policymaking Process}

Many projects described aspects of the policymaking process as being cumbersome. The bureaucracy of the institutions involved, as well as lengthy decision-making processes, tended to slow down or hinder the policy campaigns of local projects. While seasoned veterans of the legislative process better understood this legislative labyrinth, local project directors often spoke of frustration in managing it.

Gaining access to policymakers was one issue faced by local projects. Project directors found that policymakers often insulated themselves from the public with several layers of staff and commented on how the process of meeting with a policymaker involved successfully navigating one or more gatekeepers. Many said that they had to first develop relationships with legislative aides prior to gaining any "real" time with a policymaker. For many, this added yet another layer to a long campaign and could become an organizational barrier. Nonetheless, several project directors persisted and reported on the value of presenting materials to aides. These mini-presentations, if successful, led to three results: (a) getting the material passed on to the policymaker(s), (b) gaining personal access to the policymaker at a later time, and (c) making an ally of the aide.

If and when access was gained to policymakers, the goal was to solicit their support. While project directors understood this basic tenet of policymaking, several commented that it was not an easy task. Effective presentations, according to those heading the local projects, depended on recognizing and understanding the policymaker's situation, context, and making use of the local data that had been collected. In fact, most final evaluations analyzed for this study mentioned the value of using the local data in an effort to sway policymakers. The relative persuasiveness of these presentations, then, was frequently predicated on the access to, and richness of, the local data collected by the local project in preparation for these presentations.

Yet, many project personnel noted that even the best presentations did not always lead to policy success. If a policymaker or group of policymakers became an opponent of smoke-free policy, project directors noted that it was next to impossible to get policy adopted. Sometimes a policymaker was a smoker, which oftentimes spelled doom for securing policy. Other times, a policymaker or group of policymakers felt strongly about the arguments that were given in opposition of potential smoke-free policy.

More often than not, however, policymakers were not stalwarts against smoke-free policy; rather, they were ambivalent toward any new unknown policy and were willing to move policy forward only when they viewed it as popular with their constituents, thus displaying a certain degree of risk avoidance. The campaign's job was thus to demonstrate support of policy from policymakers' constituents. Sometimes this proved difficult; as one project director reported:

Our local council gave us assurances that things would work out, but when push came to shove, the council was not very responsive to new policy. We found that they were not entirely against new policy, but at the same time they were not on a soapbox advocating for it either. This was especially the case in the beginning.

Although the learning curve was fairly steep for local project personnel charged with getting smoke-free policy adopted, many reports made similar observations when discussing how the projects were able to overcome the many obstacles to getting policy enacted. For example, several final evaluation reports described how vital it was to provide policymakers precedents and past smoke-free successes since decision-makers were sometimes hesitant, according to the reports, of being the first to take a stance on something that may have an adverse effect on some constituents, as tobacco-control policies inevitably do. Local projects thus found it helpful to show policymakers evidence of public acceptance for the same policy in neighboring communities, or even past tobacco-related successes in their own jurisdiction. The precedents tended to legitimize the current proposed policy and were deemed effective by project directors. One report stated:

In every case, mention was made of other communities that had implemented similar ordinances and measures. This effect cannot be overstated: no local action would have been likely without the evidence of reasonableness afforded by precedent. The presence of pending state-level legislation provided a similar legitimacy to local control efforts.

\section{Enforcement}

The success of a smoke-free policy, like any policy, depends not only on getting adopted, but also on getting implemented. It is one thing to adopt a no-smoking policy and another thing entirely to enforce it. This distinction was an issue and became an additional organizational barrier that local project personnel had to overcome.

Many final evaluation reports noted that enforcement was raised as a key concern prior to the adoption stage of policy-work during conversations with city councils, county boards or supervisors, and event boards and coordinators. Decision-makers tended to be reluctant to pass any smoke-free policy unless issues of how the policy would be enforced were properly addressed. Opponents of 
policy understood this dynamic and often tried to capitalize on it. For example, one report cited a rhetorical question asked by a policymaker during a public meeting: "Is that what we want our police spending their time on?" Projects had to take this into account when pitching a local smokefree policy to decision-makers. Another report quoted a local commissioner from a coastal community:

We're somewhat afraid to over regulate or over legislate. We just don't want to enact a law for the heck of it, especially if you can't enforce it. We can't even keep the dog poop off the beach. How can we enforce this new law? It just may be an exercise in futility.

Local projects used a variety of methods to allay the concerns of policymakers. Several project directors and coordinators explained to policymakers the value of educating the public through signage and information, rather than thinking of enforcement as a policing issue. For other local projects, the issue of enforcement was addressed in the policy itself. One report said, "We made sure enforcement was described in detail in the actual ordinance, including the signage that would take place and the appropriate responses to policy violations."

Although the enforcement, or lack thereof, of smokefree policy tended to worry public officials, in reality, project directors revealed that signage and small educational campaigns often created situations where citizens felt emboldened to self enforce ordinances. This was particularly the case in beach communities where locals were aware of the law and took on the role of enforcers by pointing out the law to tourists. Furthermore, final reports also described how education (in the form of pamphlets and enforcement warnings), in combination with signage in outdoor venues such as parks, beaches or recreational areas, effectively created an ongoing norm change as it related to smoking. Such a change, project directors contend, was the ultimate goal of policy and made the issue of enforcement negligible. Moreover, post-policy adoption observations and litter pick ups continually revealed that smoking indeed declined due to the combination of signage and education.

\section{Staffing and Resource Issues}

Final evaluation reports indicated that a major barrier in getting local smoke-free policies adopted was management issues within a local project's own department. Such budgetary concerns are faced by a wide array of organizations and community health projects $[7,8]$. Yet, in reference to policy adoption campaigns as described in the final evaluation reports, relationships that were built and forged with specific staff and local policymakers could be lost once influential project staff departed. Several final evaluation reports described how staff reduction and turnover created major setbacks in the work of securing passage of local policies because so much of this process relied on personal relationships that had been developed and nourished over years.

Much of the staff reduction was attributed to the lack of resources targeted for the projects. More money directed toward fewer staff-in an effort to stymie staff turnovermeant a smaller staff taking on a larger workload. For instance, several projects reported that shortages of their program staff (or a "thin staff," as one report noted) impeded their work, causing them to rework timelines and adjust their range of activities, which became a barrier for getting policy enacted and implemented.

Some reports suggested that more resources to expand staffing would enable local agencies to diversify and expand their campaigns and thus make them more effective. In reality, the projects received the same amount of money they had been receiving for the past few years; however, because staff and administrative costs rose, the local projects had to extend their resources further. In some cases, budgetary limitations forced local projects to choose among competing objectives, to the point that a common refrain in several reports was having to "do more with less." One project summed this up nicely:

Although we would have liked to work on objectives related to the [Native American] Indian casinos in our county, we quickly realized that based on our resources and the effort needed to get smoke-free policy passed, such a project would be unmanageable. Essentially, our decision was an economic one.

A partial solution for many projects has been to recruit volunteers from the local community to expand the organization's capacity. Sometimes these were drawn from a project's coalition members who could act as "champions" for the cause. Several projects reached out to youth volunteers via high school and university-affiliated student organizations, an effective approach since these young people were already organized and could provide much needed vigor and enthusiasm to local policy campaigns. This set up a symbiotic relationship by providing youth organizations an opportunity to participate in local issues while offering much needed staffing and resources to the local projects.

\section{Political Polarization: Opponents to Local Smoke-Free} Policy

Because enacting policy is inherently a political process, polarization among policymakers, as well as among their constituents, occurred naturally and created opposition between tobacco control advocates and their adversaries. 
Opposition often came from key policymakers who had power over their local boards. In some cases, this polarization was enough to effectively kill any new proposed smoke-free legislation. Political arguments tended to coalesce around smokers and non smokers, rural and urban cohabitants, and along party lines where the smoke-free policies could be viewed as either progressive or part of government expansion. Sometimes, all these political dynamics played out simultaneously at the expense of the local projects working to move a smoke-free agenda forward. Final evaluation reports indicated that in many cases the policy-countering arguments were made by influential policymakers who were also smokers themselves.

\section{Economics: "It's Bad for Business"}

A common theme that local tobacco-control projects faced in attempting to secure passage of outdoor smoke-free policies regarded the local business economy and communities' concerns regarding a policy's potential negative effect on business. Fears surfaced in a number of jurisdictions that the proposed policies regulating smoking would drive paying customers away. For example, restaurant owners and special event coordinators were concerned about smoke-free outdoor dining policy or ordinances dealing with events taking place downtown.

There was an outcry from some of the businesses downtown when they heard about the proposed [smoke-free] policy. Business owners were interviewed and it ran in the papers that they were afraid of losing money if the policy passed.

Anxiety about the potential negative impact of smokefree policy on local businesses occurred most often in counties and municipalities where communities still had pockets of strong resistance from a small but vocal opposition. Communities dependent upon tourism also faced major opposition from the local business community due to worries that those visitors coming from jurisdictions and states with less smoking restrictions would not return. These concerns tended to be most pronounced at high profile local events and in beach towns where business people counted on pedestrian foot traffic and "overflow" from attending local and county fairs, farmers' markets, and annual parade and downtown promotional events. In some cases, projects were never able to fully allay the fears of board members and were thus unable to secure local ordinances at fairs and local events.

We tried every which way, but in the end, the council was afraid to pull the trigger because of all the concerns of the local business community. It actually was only a few business owners [who were adversaries], but economics is everything. It did not help that some of the council members were friends with the most vocal of the business owners.

Projects that successfully surmounted this problem credited an effective presentation to the policymakers, using local data demonstrating the attitudes of local residents, presenting data from other jurisdictions in which similar policies were enacted, and offering reliable research data on the subject of tobacco policies and economic effects.

In fact, these economic-related objections were nothing new to the tobacco control effort since similar issues emerged when California first enacted the indoor smokefree workplace laws that regulated restaurants [9] and later bars and taverns [10]. In these previous cases, while the initial outcry from the business community garnered media publicity, studies found that there was virtually no negative economic impact for both the restaurant and bar industry once these laws were implemented [11, 12]. Thus, project leaders had an arsenal of empirical evidence to convince the local businesses, community members, and policymakers that smoke-free policy would not negatively affect local commerce. Through collecting local data, educating the community, understanding the local political climate and making effective presentations to policymakers, projects often were successful in overcoming these economicrelated arguments [13].

\section{Individual Rights: "It's a Free Country"}

Many reports noted that one of the most passionate objections to tobacco control in any form centered on the issue of proposed regulations' infringement of citizens' personal freedoms. Local officials, event boards and surveyed individuals had reservations regarding proposed legislation because "people should be able to do what they want to do," as was quoted in one report from a survey respondent.

The individual rights argument is one of the arguments that the tobacco industry promoted [14], appealing to both smokers and non-smokers' sense that America is the land of the free, based on individual freedoms, and policy making outdoor areas smoke-free usurped this "natural" freedom and citizens' "civil rights." Smoke-free policies were thus conveyed as "anti-American."

This anti-government backlash made it difficult for local tobacco control projects to find sympathetic decisionmakers, especially in the smaller rural communities where any government intervention was viewed with a wary eye, according to several reports. For instance, some reports described cases where editorials in local newspapers both ridiculed the negative health impact of outdoor secondhand smoke and also cast enforcement as "costly" and 
"impossible." Local policymakers tended to see proposed smoke-free ordinances as extreme regulations of "big government" and respondents to local public opinion surveys stated that smoking policies "...take away freedoms" and surmised that, "People need to be able to smoke somewhere." One report noted the following:

In this county the prevailing attitude was summed up by another Fair board member who said sarcastically, 'Why don't we just make the whole Fair smoke-free and if anyone is smoking we'll just take 'em out in the parking lot and shoot 'em.'

Yet, it was not simply rural communities where this sentiment existed. A report from a larger county in the San Francisco Bay Area cited a quote from a city council member:

Personally, I'm really in favor of this proposed law. I hate cigarettes, and it would be better for everybody if they were not smoking or littering on our beaches. But we have things called "civil rights" here in this country. We've been losing civil rights lately in the US.

These personal rights arguments were countered by the suggestion that smokers infringed upon the rights of nonsmokers whose health was threatened by secondhand smoke. Projects made it clear that their job was to protect people-especially children-from the harmful dangers of secondhand smoke. In this way, one's personal rights were not viewed as "personal" when the action of one detrimentally affected the rights of another. As one project director stated, "Non-smokers have personal rights too. They have the right not to ingest secondhand smoke from tobacco users."

\section{Local Political Orientation: Opposition in Many Forms}

In examining the contextual forces related to this issue, we found that more affluent and populous counties exhibited far less opposition to tobacco control measures than did rural and less populated counties. Furthermore, an analysis of final evaluation reports revealed that it was far easier to find "champions" in the more affluent communities with a history of proactive tobacco control work who were willing to join well-mounted campaigns than it was in rural counties where tobacco use was more prevalent and still relatively acceptable.

For example, in one fairly populous Northern California beach county, the final evaluation report painted a picture of a progressive community whose policymakers were very receptive of the efforts of the local project, resulting in unanimous approval of smoke-free beach and park ordinances. In contrast, local projects in the rural counties discussed working with local officials who tended to be conservative in nature, supported local economic concerns and were adamant that new policies effectively curtailed individual rights.

When they encountered strong opposition, projects reported "taking baby steps" toward more stringent antitobacco policy, rather than proposing sweeping changes that have been enacted in some other municipalities. This strategy tended to be used when adopting smoke-free policies at fairs and rodeos, where strong, loud protests from smokers were often supported by the tobacco industry, which has historically contributed money and products to such events [15]. One project from a rural county acknowledged the resistance:

There is a small subset of individuals that includes what the community refers to as 'diehard' smokers, who believe that there should be a laissez faire attitude toward tobacco control. Unfortunately, this resistance was not unusual for us.

Yet, it was not always simply a rural versus urban issue. For instance, in one urban county the local project had success in establishing a smoke-free policy at one of the local colleges. They thus assumed that they could implement similar measures at the two other community colleges within the same county. However, this work was derailed by a small group of smokers at one of the colleges who were able to get the Classified Employees Union to threaten to file a grievance if one more college adopted a restrictive smoking policy. College administrators, already ambivalent about the smoke-free policies, instantly shut down any potential policy. In another urban area, a local Gay Pride Festival considered enacting a voluntary smoke-free policy. However, the smoke-free policy was met with resistance, revealing yet again that polarization was not simply an issue faced by rural projects. In this latter case, a final evaluation report cited quotes from key informants who were upset with the proposed smoke-free policy, demonstrating opposition's many voices.

Combining two such hotly debated topics is not appropriate for a day when we are trying to focus only on gay pride. The tobacco agenda is its own political battle for everyone, not just gays.

Another respondent stated:

I think that the tobacco coalition is taking advantage of an underdog community to press its own agenda. It should be enough that it is a city rule not to smoke in the preserve. Pride people don't have to start trying to control the health habits of their community, we have enough to worry about already. 
Although some counties and local communities resisted implementing smoke-free policies-in part due to heavy pockets of resistance-several final evaluation reports commented on the one cultural universal that provided a healthy antidote for those entrenched in laissez faire smoking regulation: the welfare of children. Hence, if the local project could engage youth in the campaign, positive results tended to ensue. In this manner, when the welfare of children was articulated-vis-à-vis tobacco use-regardless of the obstructive opponents, it tended to transcend county characteristics, political climate, and obstructive opponents. This was yet another reason why tapping into youth volunteers was deemed a key strategy for local projects [13].

\section{Discussion}

This study investigated the barriers confronted by California's local tobacco control projects in their effort to adopt and implement smoke-free policy in local recreational spaces, such as parks and beaches, as well as at venues for community events such as fairs and farmers' markets. Overall, the barriers were grouped in three primary areas: organizational barriers, politically polarization, and local political orientation.

The findings align with the barriers associated with adopting policy more generally [16], particularly in the organizational realm. Yet, the political polarization with regards to tobacco-related issues creates unique challenges related to health policy and specifically to tobacco control. These included the notion that smoke-free laws were "bad for business" and that laws or policies violated one's individual rights.

Although we have chosen to focus on the barriers faced by local tobacco control organizations in adopting and implementing local smoke-free policies, it is important to note that in the time analyzed for this study (2004-2010), hundreds of local smoke-free policies have been enacted all over the state of California. Local tobacco control organizations have enjoyed great success in campaigning for, and securing adoption of smoke-free policies. Nonetheless, our intent in examining the barriers in adopting and implementing local policies was to better understand ways in which tobacco-control organizations may create successful plans of action in enacting local smoke-free policy by anticipating and adjusting to potential challenges and barriers. In one way, the barriers identified in this study underscore the need for an organized action plan in adopting local tobacco policy [5]. Thus, in recognizing these barriers, we also have identified potential strategies to overcome or offset the barriers.
These include: (1) having a "champion" who helps to carry an objective forward; (2) tapping into a pool of youth volunteers; (3) collecting and using local data as a persuasive tool; (4) educating the community in smokefree policy efforts; (5) working strategically within the local political climate; and 6) demonstrating to policymakers the constituent support for proposed policy [13]. In addition to these strategies, it is also evident that much of the success of local smoke-free policy derives from previous policy adoption and implementation [17, 18]. It is thus important to recognize past policy successes around the state and especially in surrounding local areas. This approach invariably leads to a domino effect in which local jurisdictions understand they are part of a larger movement.

The results of this study also demonstrate how a failed intervention, one where policy was not adopted in a particular funding cycle, often provided the local projects with insight useful to them in future policy-campaigns. Moreover, this insight-when disseminated through meetings, conferences and roundtables-often made it easier for neighboring jurisdictions and other local projects to begin their own effective campaigns.

The final evaluation reports revealed not only the barriers in enacting outdoor smoking policy, but also that community norms have changed, and continue to change, as they relate to smoking and secondhand smoke. In this manner, efforts to combat smoking and secure passage of smoke-free policy increase the denormalization process, both socially and environmentally. As people become accustomed to smoke-free areas, resistance to such policies decreases. Moreover, people who smoke also have become more aware of the effect of their usage of tobacco on others. Such attributes generate a larger awareness and mindfulness in our communities that we suspect will someday have a global effect.

Across the state of California, many local communities have adopted and implemented smoke-free policy. The future of anti-tobacco work rests with local communities in overcoming the challenges and barriers that arise, creating effective action plans and responses. As such, future studies should continue efforts to improve our understanding of the interactive factors affecting the adoption of policy.

Acknowledgments The authors would like to thank all the project directors from the local projects that submitted the final evaluation reports used for this study. This work was supported through a contract with the California Department of Public Health, Tobacco Control Program.

Open Access This article is distributed under the terms of the Creative Commons Attribution Noncommercial License which permits any noncommercial use, distribution, and reproduction in any medium, provided the original author(s) and source are credited. 


\section{References}

1. Glantz, S. A., \& Parmley, W. W. (1995). Passive smoking and heart disease: Mechanisms and risk. Journal of the American Medical Association, 273, 1047-1053.

2. He, J., Vupputuri, S., Allen, K., Prerost, M. R., Hughes, J., \& Whelton, P. K. (1999). Passive smoking and the risk of coronary heart disease: A meta analysis of epidemiological studies. New England Journal of Medicine, 340, 920-926.

3. Eriksen, M. P., \& Cerak, R. L. (2008). The diffusion and impact of clean indoor air laws. Annual Review of Public Health, 29, 171-185.

4. Roeseler, A., \& Burns, D. (2010). The quarter that changed the world. Tobacco Control, 19, i3-i15.

5. Francis, J. A., Abramsohn, E. M., \& Park, H. Y. (2010). Policydriven tobacco control. Tobacco Control, 19, i16-i20.

6. Klepeis, N., Ott, W. R., \& Switzer, P. (2007). Real-time measurement of outdoor tobacco smoke particles. Journal of Air \& Waste Management Association, 57, 522-534.

7. Thompson, A., Boardley, D., Kerr, D., Greene, T., \& Jenkins, M. (2009). Public policy involvement by health commissioners. Journal of Community Health, 34, 239-245.

8. Altman, D. G., Endres, J., Linzer, J., Lorig, K., Howard-Pitney, B., \& Rogers, T. (1991). Obstacles to and future goals of ten comprehensive community health promotion projects. Journal of Community Health, 16, 299-314.

9. Bartosch, W. J., \& Pope, G. C. (2002). Economic effect of restaurant smoking restrictions on restaurant businesses in Massachusetts, 1992-1998. Tobacco Control, 11, ii39-ii42.
10. Alamar, B., \& Glantz, S. A. (2007). Effect of smoke-free laws on bar value and profits. American Journal of Public Health, 97, $1200-1202$.

11. Scollo, M., Lai, A., Hyland, A., \& Glantz, S. A. (2003). Review of the quality of studies on the economic effects of smoke-free policies on the hospitality industry. Tobacco Control, 12, 13-20.

12. Chaloupka, F. J., \& Warner, K. E. (2000). The economics of smoking. In A. J. Culyer, \& J. P. Newhouse (Eds.), Handbook of health economics (pp. 1539-1627).

13. Satterlund, T. D., Cassady, D. L., Treiber, J., \& Lemp, C. (in review). Local policy strategies for tobacco control: Lessons from 20 policy initiatives on smoke-free recreation areas.

14. Katz, J. E. (2005). Individual rights advocacy in tobacco control policies: an assessment and recommendation. Tobacco Control, 14, ii31-ii37.

15. Feighery, E., Borzekowski, D. L. G., Schooler, C., \& Flora, J. (1998). Seeing, wanting, owning: The relationship between the receptivity of tobacco marketing and smoking susceptibility in young people. Tobacco Control, 7, 123-128.

16. Cooksey, J. A., \& Krieg, R. M. (1996). Metropolitan health policy development: Barriers to implementation. Journal of Public Health Policy, 17, 261-274.

17. Blaine, T. M., Forster, J. L., Hennrickus, D., O’Neil, S., Wolfson, M., \& Pham, H. (1997). Creating tobacco control policy at the local level: Implementation of a direct action organizing approach. Health Education \& Behavior, 24, 640-651.

18. Mintrom, M. (1997). Policy entrepreneurs and the diffusion of innovation. American Journal of Political Science, 41, 738-770. 